\title{
Developing Instructional Design Agents to Support Novice and K-12 Design Education
}

\section{Introduction}

Artificial intelligence (AI) and its potential to dramatically reshape areas of application has drifted into and out of our public and academic discourse over several peroids ${ }^{1}$. With advances in computing and cloud technology it has seen another revival garnering attention as Google's Alphago ${ }^{2}$, a simulated Go player, resoundingly defeated the most skilled human players, personal assistants such as Siri or Alexa use natural language processing to respond to our queries and commands over a bevy of electronic devices and the National Science Foundation makes numerous proposal calls emphasizing AI applications, such as the Future of Work at the Human-Technology Frontier ${ }^{3}$ which seeks new vision and research into human-technology partnerships.

The areas of design and education have also seen waves of interest in AI, from the use of AIpowered design agents to assist designers in the design process within design research ${ }^{4-6}$ to the deployment of intelligent agents in intelligent tutoring systems to monitor and support students learning in physics, math and other fields within education research ${ }^{7-10}$. To date, however, there appears to be little work that addresses the union of these two bodies of work: how AI might assist in design education. In light of the well-documented difficulties novice designers have in learning and practicing design ${ }^{11-13}$ and the increased interest in teaching design in K-12 classrooms ${ }^{14}$ and the limited experience many K-12 educators have with engineering education and design more specifically ${ }^{15-16}$ we propose instructional design agent's, computer embedded intelligent agents who can perform design practices or processes, as an approach for scaffolding new and novice designers' learning. Toward this end, we synthesize research on intelligent agents in education and AI powered design agents to develop an instructional design agent framework. This framework outlines the major components of these agents and the key pedagogical and technological decisions that design educators and researchers need to make for constructing an instructional design agent and associated curriculum. After presenting the generic framework, we provide an early demonstration example, based on our ongoing work, involving a set of instructional design agents that scaffold divergent and convergent design search process in a solar farm design activity.

In design education, the growing use of computer-aided-design, including open-source platforms like FreeCAD or other digital design environments $\left(\mathrm{e} . \mathrm{g}^{17}\right)$, provide an opportunity for embedding instructional design agents within these systems. For this work, we define intelligence and more specifically artificial intelligence as the capability of a computer system to perform some activity toward some goal in an uncertain environment ${ }^{18}$. This is sometimes called performance intelligence ${ }^{19}$. For design, this translates to the ability of some computer system's capacity to engage in some part of the design process or design practices in an uncertain environment toward some goal.

The paper is structured as follows. First, we review literature in AI-powered design agents, henceforth called design agents, and intelligent agents in education. Next, drawing out key insights from these bodies of literature and our initial efforts in developing design agents for 
education, we present the instructional design agent framework and its core components. Following this, we present a demonstration case of how the instructional design agents could be implemented, briefly outlining our platform, the activity students engage in, a small pilot study, results and discussion. Finally, we close with limitations, implications and future work.

\section{Literature Review}

\section{Intelligent Agents in Education}

An intelligent agent is an autonomous system that can sense and act on the given environment in pursuit of its own agenda ${ }^{20}$. There are four basic properties of an intelligent agent, it can: 1) run without direct intervention of humans (i.e., autonomy), 2) communicate and interact with humans and other agents (i.e., social ability), perceive the environment and respond to changes in it (i.e., reactivity), and exhibit goal-directed behavior (i.e., pro-activeness ${ }^{21}$ ). Furthermore, the most important property of an intelligent agent is that the agent is conceptualized or implemented using human-like concepts, such as knowledge, belief, intention, and emotion ${ }^{21}$.

With capacity for reasoning, planning, natural language processing and other human intelligence abilities, intelligent agents have been deployed in many domains to assist human's work. Education, where teachers and learners struggle to cover more material while meeting rising expectations and standards, is a ripe arena for intelligent agents to have a large impact on the practices therein. Following this, intelligent agents for education have been extensively researched over the past three decades. Perhaps the most well established and popular educational platforms that use intelligent agents are intelligent tutoring systems (ITS, e.g. ${ }^{22-23}$ ). ITS are computer programs that provide individualized instructions to learners by computationally or statistically modeling learners' knowledge, cognitive or other related states and contrast students' states with an expert model of a given domain to provide appropriate instruction ${ }^{10,24}$. While not all ITS explicitly use intelligent agents, many ITS use agents for tasks such as posing questions to students ${ }^{25}$, providing students' feedback ${ }^{10,26}$, and responding to students' questions ${ }^{27}$.

More specifically within the scope of engineering education, ITS have seen reasonable traction, being used to teach several subjects such as circuits ${ }^{28-29}$, thermodynamics ${ }^{30}$, software engineering $^{31}$, computer-numerical control operations ${ }^{32}$ and several others ${ }^{33-34}$.

Intelligent agents can act in different roles within a learning environment. For example, agents can be experts, mentors, and motivators ${ }^{35}$; learning companions ${ }^{36}$; guides, and teammates ${ }^{37}$. Mentor is the most common role that intelligent agents assume. The mentor agent takes on the characteristics or persona of a "person" who has advanced experience and knowledge and uses these to collaborate with the students toward a shared goal ${ }^{38}$. Researchers have argued that, to be a successful mentor, intelligent agents should have an appropriate persona, and control pedagogical interventions with students ${ }^{38}$.

The vision of intelligent agents in education has shifted over the past several decades. Initially the goal of these agents was to enhance domain knowledge and skills, which has gradually expanded to incorporate the social aspects of human-agent interactions (e.g., motivation and 
emotion ${ }^{39}$. Furthermore, the application of intelligent agents has extended to more knowledge and skill domains over time. The earlier application focus on the well-structured domains (e.g., math ${ }^{40}$ ), while newer works has expanded to ill-structured domains (e.g., leadership training and decision making in stressful situations ${ }^{37}$; strategic CAD skills ${ }^{41}$ ).

\section{Design Agents}

Computationally encoding design intelligence, as exemplified by the ability to conduct design practices or behavior, has been the subject of considerable research in design. Often design intelligence is encoded into agents in a computing environment who then engage in some design practice or behavior, ${ }^{62-44}$. This review briefly outlines some of the common motivations behind the development of design agents as well as providing a high-level overview of the software architecture used in these systems.

A frequent motivation or target goal of design agent systems is to create intelligent assistive tools for designers, often by having agents search a design space for solutions ${ }^{6,43,45-46}$. These design agent systems typically employ multiple agents, called multi-agent systems, which includes multiple agents with the same role as well as differentiated roles across agents ${ }^{6,43,46-47}$. Some of the roles design agents may take on include search/configuration agents that create solutions $\mathrm{s}^{4-5}$, 43-44 to evaluators that assess the performance of a generated solution ${ }^{44-46}$ to manager agents that oversee and intervene in the design search ${ }^{5,43}$. Multiple agents of the same type may be included to perform similar actions on different aspects of the design, such as individual evaluation agents that each evaluate a design based on one of a set of performance criteria ${ }^{46}$ or as an adaptive population of search agents with different preferences ${ }^{5,43}$.

These groups of design agents are then situated within a larger system which control their integration and joint execution of some type of design practices or behavior. While the exact details of the system architecture differ by research study or architecture model employed, many models employ well-established artificial intelligence algorithms, such as variations the genetic algorithms $\mathrm{s}^{5,43,48}$ or simulated annealing ${ }^{46}$, at the system level.

Another way in which design agents have been deployed is to simulate human designers. These design agents can be the subject of research studies in lieu of human designers, as there are often constraints or limitations in studying human designers for a given topic. McComb, Cagan, Kotovsky and colleagues have done considerable work in this arena and developed the Cognitively Inspired Simulated Annealing Teams (CISAT) ${ }^{42}$ and Heterogeneous Simulated Annealing Teams (HSAT) ${ }^{49}$ algorithms to represent design teams' design behavior ${ }^{50-51}$. The CISAT algorithm employs a modifiable number of design agents who select a search direction, generate, evaluate, and finally recommend or decline self-generated design solutions. CISAT also incorporates several design behaviors into its agents such as asynchronous interactions with other 'team' members and satisficing. HSAT is largely identical to CISAT, but incorporates fewer design behaviors into its operations. These algorithms have been used in various applications to simulate designers, for example, in ${ }^{51}$ CISAT was used to simulate a set of designers who learned design operation sequences to improve their design and a set who did not, to compare how the learning of sequences affected final design artifact performance. 
A less common way in which design agents have been deployed is as instructional agents. Given the paucity of work in this area, it is difficult discuss common patterns in architecture, but in general these agents are more student facing, aiming to improve some aspect of learning in design projects ${ }^{41,52}$. For instance, Hu and Taylor ${ }^{41}$ modified the open-source computer-aideddrafting (CAD) platform, FreeCAD, to include an intelligent tutoring system, which acts as an agent, to assist students in the operations needed to make specific geometric objects. The system or agent exhaustively analyzes the potential operation sequences to make some geometric object students are tasked with creating and when students diverge from creating the object, it suggests multiple routes for putting their design on track. By offering multiple routes for correcting their design, the agent aims to teach strategic flexibility or the ability to identify and execute multiple creation routes for a designed object.

\section{What this paper contributes}

In this manuscript, we build on two streams of work. First, we draw on intelligent agents and intelligent agents in education including the notion of what agents are, what roles agents might portray and what agents can provide to students in educational settings. Second, we draw on computational design including the architecture of design agents, the types of design intelligence that has been computerized and what design agents can provide designers. These lines of work are integrated to propose instructional design agents which can help scaffold key challenging parts of the design process or design practices to assist early or novice designers in getting exposed to and starting to learn how to design.

Learning design can be challenging for novice or early designers for an array of reasons; we briefly highlight a few central reasons here. First, design problems are often ambiguous ${ }^{11}$ and may have a high degree of uncertainty ${ }^{53}$. Second, most designers and especially novice designers will be limited in their knowledge of the problem or capacity to evaluate all possible solutions or considerations, a condition sometimes called bounded rationality ${ }^{54}$. Importantly, even a relatively simple design problem may have a design space beyond what an individual designer can exhaustively explore. A third challenge arises in that research has identified that designers often fixate $^{55}$ on certain design features or design artifacts early on, leading them to stick with less promising designs despite mounting evidence of their limitations. These few points, while far from exhaustive illustrate some of the challenges facing novice designers: it can be difficult to find a heading or navigate through design problems; designers will have to learn and modify their strategy throughout the process and designers will need to recognize and mitigate practices that may inhibit their ability to find promising design solutions. For these reasons and others, design agents may be able to support novices in learning and developing as designers.

In the next section we elaborate on these instructional design agents through a tripartite framework encompassing the role of agents, the role of students and the interactions between the two.

\section{Instructional Design Agents Framework}

Instructional design agents are agents in a computer environment who encode some segment of design intelligence, such as the ability to conduct some part of the design process or some design 
practices, for the purposes of helping students learn design or educators teach design. They are deployed in design challenges or projects as is common for learning design. Instructional design agents do not replace the typical curricular or project structure of design learning in the classroom; instead they are woven in with the larger instructional design. Thus, the framework presented here will discuss both the design instructional design agents and curriculum/project in which they are embedded. It is important to note given the complexity of developing and integrating instructional design agents into design projects, early implementations may rely more on the curricular/project structure to frame and scaffold the agents. As the instructional design agents and curriculum evolve, more of these responsibilities may be incorporated into the agents themselves.

In applying the instructional design agent's framework, design educators should start by considering what they want their students to learn about design. Educationally speaking, the instructional design agents within this framework act as an educational scaffold or means to support less experienced students to successfully engage and complete an activity they might otherwise be unable to complete ${ }^{56}$. While scaffolding originally referred functions performed by experts or teachers, it may also be performed in technology-supported learning environments ${ }^{57}$. Therefore, in addition to identifying the parts or scope of design an educator wants to introduce students to, they should additionally consider how the instructional design agents might assist students in navigating and completing the design challenge. The rest of this section will delineate the major considerations needed to setup this scaffolding.

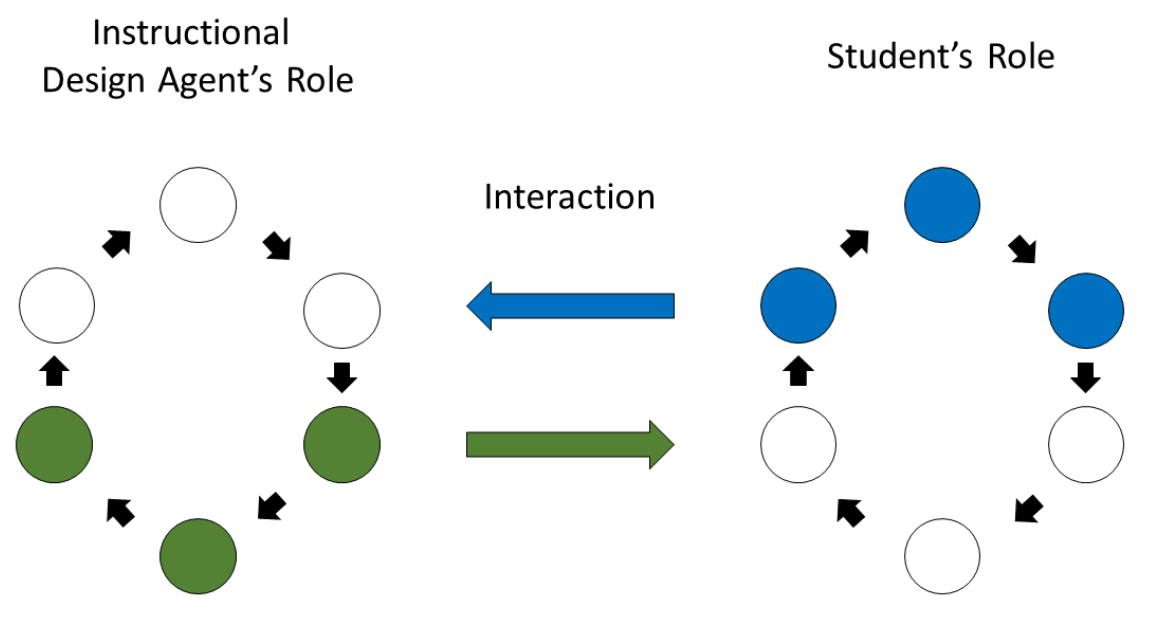

Figure 1: The Instructional Design Agent Framework

In order to realize the implementation of instructional design agents in design projects, there are three pedagogical and associated technological decisions to consider: the role of the agents, the role of the student and the interactions between agents and students. Collectively, these form a tripartite framework for implementing instructional design agents, graphically depicted in Figure 1. In the figure, both the instructional design agents and student are responsible for sections of 
the design process or respective design practices. Note that the design processes depicted in the figure are generic; there are many ways to operationalize or conduct the design process ${ }^{58}$ and this model can be flexibly applied to these different processes. In the rest of this section, we address each component of the framework by defining them and outlining the key curricular and technological decisions educators will need to consider. An overview of the following three sections is provided in Table 1.

\begin{tabular}{|l|l|}
\hline Table 1 Instruction Design Agent Framework Components and Key Decisions \\
\hline Instruction Design Agent's Role & $\begin{array}{l}\text { - What design intelligence will the } \\
\end{array}$ \\
& $\begin{array}{l}\text { - Wents embody } \\
\text { - What roles will the agents assume }\end{array}$ \\
\hline Human-Agent Interaction & $\begin{array}{l}\text { - Level of scaffolding in interaction } \\
\text { - What type of interaction }\end{array}$ \\
\hline Student Role & - Interaction with multiple agents \\
& $\begin{array}{l}\text { - Scope of student's responsibilities for } \\
\text { the design challenge }\end{array}$ \\
\hline
\end{tabular}

\section{Instructional Design Agents Role}

What is the role of an instructional design agent? The instructional design agent's role can be defined as the set of responsibilities and activities that fall within an agent's intended purpose, which when viewed holistically, demarcate its position or part to play within the design challenge.

In light of this definition, we turn to three points of consideration needed to develop this role: what design intelligence will the agent(s) embody, what specific types of roles will the design agent(s) assume and how many design agents should be employed.

We discuss the design intelligence agents embody first, as this has implications for the other decisions about the agent's role(s). There many ways in which intelligence can be defined or measured $^{17}$, however one way in which it can be defined is as the capacities or the tasks some system (whether biological or computational) can complete or learn to complete to address some goal $^{18,59-60}$. In this context, this can be translated to a systems capable of performing some set of design practices or parts of the design process toward some goal. The design practices an instructional design agent perform are a direct reflection of its responsibilities within its role and the larger design challenge or project. Note also that this is a definition of domain-specific artificial intelligence or weak $\mathrm{AI}^{59}$, where the domain is the area of design education.

Past work on design agents in the broader design literature have developed systems capable of performing different design practices. Two common design practices these agents engage in are detailed search or optimization of a relatively well-defined design-space (e.g., ${ }^{51}$ ) and a more conceptual search of design alternatives where constraints are open to change, leading to searches across different parts of the design space (e.g. ${ }^{6,43}$ ). Note, in practice there are many similarities in between design agents across these two areas of design behavior. Computationally, 
both genetic algorithms $s^{4,6}$ and simulated annealing ${ }^{42,46}$ have been used to partially or completely structure design agents' behavior for these two search practices. Briefly, genetic algorithms metaphorically evoke evolutionary concepts to structure the search of a design space, typically creating a 'generation' of designs, testing them against some objective, keeping the fittest and using those remaining to create a new generation. This process is performed iteratively to identify promising design alternatives. Simulated annealing metaphorically evokes the annealing process in metallurgy to structure the search of a design space, starting at a high 'temperature' where there is a greater likelihood of generated designs being accepted for consideration and slowly 'cooling' or decreasing the rate of acceptance, allowing better performing designs to displace others. These two approaches illustrate ways in which design intelligence, as the capacity to perform design practices or behaviors, can be embodied by design agents and by extension instructional design agents.

While these two common approaches for computerizing design intelligence enable instructional design agents to engage in a variety of design practices or behaviors, they are limited in how much of the design process can be encapsulated or enacted by instructional design agents. Therefore, in addition to directly extending research on design agents into design education, there are also many opportunities for pursuing new avenues to embody design intelligence in instructional design agents. This holds the promise of diversifying and expanding the potential of how instructional design agents could assist early or novice designers in learning design. For example, drawing inspiration from ${ }^{46}$ use of searchable design component database for their agent system, a smart query agent could be constructed that returned a list of promising components emphasizing different trade-off considerations for detailed design or modeling. A component trade-off agent like this could help students to continue to explore, refine and optimize their design even after several decisions have been set. Another example could involve an agent that employs neural network techniques that map features of a states across a design space and transformations to that design states, similar to design heuristics ${ }^{61}$, and use this network to recommend a transformation to designers when they are unable to progress. Such an agent could furthermore 'learn' from designers' feedback about whether recommended transformations were useful or not. A heuristic design agent like this could help novice designers escape fixation or design dead-ends and encourage more divergent thinking ${ }^{62}$.

The design practices an instructional agent engages in form the foundation of the role the educator intends the agent to enact.

The next point of consideration asks what specific type of role should instructional design agent take in the design challenge? To some degree, an instructional design agent's role is constrained by the types of design practice or practices it engages in. However, it is also possible that an agent with capabilities in some design practice could implemented to take on several roles. For example, one of the most common roles intelligent agents in education take on is the role of mentor $^{38}$. An instructional design agent could act as a mentor by demonstrating good design practice or guiding a novice designer through challenging parts of the design process. Other potential roles in design could be coequal team members, junior team members or even rivals depending on the scenario. 
The role an agent takes on need not be only be framed or structured by the design practices it takes. The curriculum or instructional material for the design project can help frame the design agent because making the agents state and goals clear to the student is critical for human-agent interaction $^{63}$. For example, by introducing, the agent and textually or pictorially depicting its specific role in the project. Particularly in early development of an instructional design agent, curricular or instructional framing of the agent may be especially useful as the curriculum and technology are likely still developing.

The specific type of role an agent is should address the design educator's goals for what students should get out of the activity and is realized both through its encoded design practices and its interactions with students.

The third consideration for the instructional design agent's role asks how many instructional design agents should be incorporated into the design project? This decision relates to what kinds of design practices the agents are responsible for as well as the specific roles they assume.

In terms of the design practices agents are responsible for, this can affect the number of instructional design agents needed in several ways. First, one component of determining how many agents should be employed relates to the scope of the agents. For example, in the design literature reviewed previously some work looks to define agents with a small, focused scope, such as the single function agent (SIFA) framework (e.g. ${ }^{44}$ ), where agents have one central function and a focal parameter or design object. A SIFA may provide advice to other agents about a single parameter of a design. On the other end of the spectrum, in the CISAT platform ${ }^{42}$ agents are responsible for several functions and design variables, resulting in agents with a broader scope. Here, CISAT agents generated full design artifacts, evaluated them and stored or discarded them. While the nature of the agent's internal architecture is a technical decision that may not affect students, those agents that are student-facing, i.e. those that students directly interact with, may better operate with a broader scope, lest students get overwhelmed or confused interacting with a voluminous number of agents responsible for a microscopic level of design actions. An exception to this is if the instructional design agents intended responsibilities are small in scope; then an approach like SIFA $^{44}$ would be preferable.

A second way in which the design practices may affect the number instructional design agents is in the number of larger design practices (which may be composed of several functions) an educator wants agents to engage in. While the practice of searching a design space for new ideas may well be encapsulated by a single agent, if structure of the activity also employs an agent for offering suggestions when designers are stuck, this suggestion agent may be better implemented as a separate agent to make their roles clearer to the student. Finally, similar to how personas are used represent different types of users or customers for product design ${ }^{64-65}$ instructional design agents can have different persona's reflecting different ways in which designers may approach some practice. This could also lead to having more design agents. For instance, a suggestion agent could rely on different sets of heuristics to recommend to a designer when they are stuck.

In addition to what and how many design practices are encoded in design agents, their specific roles can affect how many design agents should be deployed. While a mentor may act as a single 
agent, team members may well be represented by several agents. Furthermore, instructional design agents who act as team members could embody different design personas to offer a novice designer a broader suite of virtual designers to interact with.

Thus the number of instructional design agents employed in a design challenge depends on what type and how many design practices an educator wants them to scaffold as well as considerations of the specific types of roles they assume.

\section{Interaction between Instructional Design Agent(s) and Student(s)}

The interaction between instructional design agents and students can be defined simply as the exchange of ideas, information or design components between these two parties in the design challenge.

The three points of consideration for the interaction between design agents and students are how scaffolded is the interaction, what type of interaction do they have and how are these interactions handled if there are multiple instructional design agents.

The way in which instructional design agents interact with students is central to determining how and to what degree students are scaffolded in the design challenge. Turning first to the degree of scaffolding the type of interaction, these can range from highly to minimally scaffolded depending on the level of assistance an educator wants to provide. For instance, take an ideation agent acting as a mentor. In a highly scaffolded interaction, this ideation agent could generate a broad selection of designs with critical design variables laid bare to showcase the depth of the design space to a student. That same agent in a minimally scaffolded interaction could provide suggestions in the form of design heuristics to designers only when they are stuck or specifically request for help, instead of automatically.

Next, turning to how students and instructional design agents might interact, the literature for intelligent agents in education, particularly ITS, demonstrate a wide variety of modes such as answering students' questions ${ }^{27}$, posing questions to students ${ }^{25}$ and providing students' feedback ${ }^{10,26}$. It is worth noting, however, many of types of interactions prevalent in the intelligent agents for education literature stem from environments focused on developing foundational domain knowledge such as physics ${ }^{9,66}$ or math $^{8,67}$ which may not always map to design education - particularly if learning goals aim toward design thinking or design cognition. Nevertheless, some of these are reasonably transferable to system built for design education such as giving feedback on students' artifacts instead feedback on their answers to questions or answering questions about science concepts as they relate to design variables of interesting ${ }^{52}$. There are also opportunities for developing new interaction modes between students and agents more appropriate to learning design such as agents who generate a list of alternative components or designs for students to consider or offer strategies for overcoming fixation. The type of design practice agents engage in, what type of role they assume and how they interact with students' are all interrelated and mutually shape each other, however it's not clear if they all have a one-to-one correspondence. Thus, there is flexibility in how these components may be integrated within instructional design agents and considerable room for research and innovation in this space. 
Similar to the type of role instructional design agents assume, the curriculum or instructional material can help frame or reinforce the interaction between students and agents. For example, design logs in the project might contain a set of prompts for students to rank or explicate tradeoffs on a list of design alternatives suggested by an agent. By selecting instructional design agents' design practices, role type and interaction type, different parts of the design process can be scaffolded to greater or lesser degrees for novice designers, enabling numerous configurations for design challenges students may participate in.

A final consideration under the human-agent interaction concerns how interactions are handled with multiple instructional design agents. When there are more than one instructional design agents, it will need to be decided if there will be any coordination or interaction among design agents themselves. If instructional design agents will need to coordinate in order to interact with the student, scaffold the design challenge or other reason(s) this may require a higher level of abstraction in the code architecture for controlling interaction such as manager agents (e.g. ${ }^{5}$ ) who oversee agents' actions or more of the overall process. Creating instructional design agents who are more responsive or reactive to changes in their environment, including the actions of other agents, would make instructional design agents closer to the definition of intelligent agents in terms of reactivity and social ability ${ }^{21}$.

\section{Student's Role}

Students role, defined abstractly, is very similar to the instructional design agent's role. Here, student's role can be defined as the set of responsibilities and activities that they are expected to engage in for the project, which when viewed holistically, demarcate their part to play within the design challenge. For students, however, they have a dual role as both designers and learners. As design challenges or projects fall under the broad umbrella of project-based learning, they have an emphasis on creating authentic, practice-oriented learning environments ${ }^{62}$ leading to student's role as designers and learners being tightly interconnected.

The primary point of consideration for this part of the model pertains to the scope of student's design process or design practices the educator intends them to participate in.

The scope of student's design process or practices for a particular design challenge reflects what the educator hopes students will learn through direct design experience. More novice or younger designers may be presented with simpler or more constrained design problems while more informed designers ${ }^{11}$ may be presented with more complex and less constrained design problems. Unlike the first two parts of the framework, this part is well established in the education and design education body of knowledge. One additional consideration under student's scope of design practice is whether the parts of the design process they are responsible for will mirror or complement what the instructional design agents perform. For instance, if the instructional design agents are implemented as team members, the student and design agents may coordinate on the same design practices, such as collectively generating design concepts, similar to how an all-human design team would function. In another example, if an educator wants to scaffold novice designers experience with challenging steps of the design process, design agents may perform these parts of the design process instead of students, as depicted generically in 
Figure 1. Following this, the interaction between a design agent and a human designer allows for their respective design responsibilities to be complementary.

\section{Demonstration of an Instructional Design Agent System}

Now that we've presented a more general framework for instructional design agents, we turn to a demonstration of it in the form of the system and associated curriculum we've been developing over the past year. Our initial work developing these agents, as well as the synthesis of intelligent agents in education and design agent's literature served as the critical foundation for abstracting out and realizing the instructional design agent framework. Now in turn, this framework assists us in pushing our particular system forward. This project is still in early stages of development, so we present results from pilot run of a design challenge focusing on divergent and convergent design search strategies.

In what follows, we first present the platform used for the activity and provide a general discussion of the instructional design agents embedded within it. Next, we present the specific design challenge and how the design agents were configured in the challenge, relating this to the instructional design agent's framework. Following this, we briefly review the study context, data collection and methods of analysis. The results are presented afterward, highlighting how students interacted with two instructional design agents and their perceptions of the agents and the agents' design assistance, followed by a brief discussion. The paper concludes with overall implications, limitations and future work under the banner of instructional design agents.

\section{Design Platform}

Energy3D is a computer-aided-design (CAD) platform which covers the design of buildings, photovoltaic systems and concentrated solar power systems ${ }^{68}$. For example, Figure 2 displays a solar farm that was built in Energy3D. In addition to allowing for the design of these systems, the platform has its own physics engine used to simulate the sun and leverages weather data from across the globe to perform several types of analysis including photovoltaic and concentrated solar power annual and daily kilowatt hour $(\mathrm{kWh})$ production and building annual and daily energy consumption. Energy3D also features a design-action focused data-logger, which captures everything from designer's transformations to the design object, analysis actions and use of Energy3D platform controls (e.g., view-controls).

Recently, we have extended Energy3D to include agents empowered by one or more genetic algorithms, an approach discussed in the framework section, to search through a design space for design alternatives. In this section we reserve our discussion of these agents to an abstract overview as they may be employed in different configurations across design challenges.

At the broadest level these design agents engage in design search practices or processes. In their current form they have been constrained to search over a small numbers of design variables as we develop the system. One of these design agents takes an input, such as a current solar rack within the CAD scene a user is viewing and conducts a search by creating multiple versions of that design, testing them against some objective, keeping those that perform well and iterating through this process $n$ many times. This ensures the agents will find a better or equivalent 
performing design every time. Once the search is complete, a summary like the one displayed in Figure 3 is displayed. This shows the starting state for a design's variables and performance and the subsequent design the agent identifies. The tabs on the lower part of the window allow the designer to review how the design variables evolved over 'generations' or iterations of the genetic algorithm. By changing parameters to design agents search, such as how many alternatives they consider or how much variability there is to newly derived alternatives, these design agents may assume different design persona's or design strategies to searching a design space.

\section{Design Challenge: Divergent-Convergent Solar Farm Design}

The design challenge asks students to design a solar farm in Energy3D with the assistance of two design agents, Bob and Carol. The goal is to design a solar farm that can generate maximum profit, with a minimum target of at least $\$ 100$, in the peak of summer in New England.

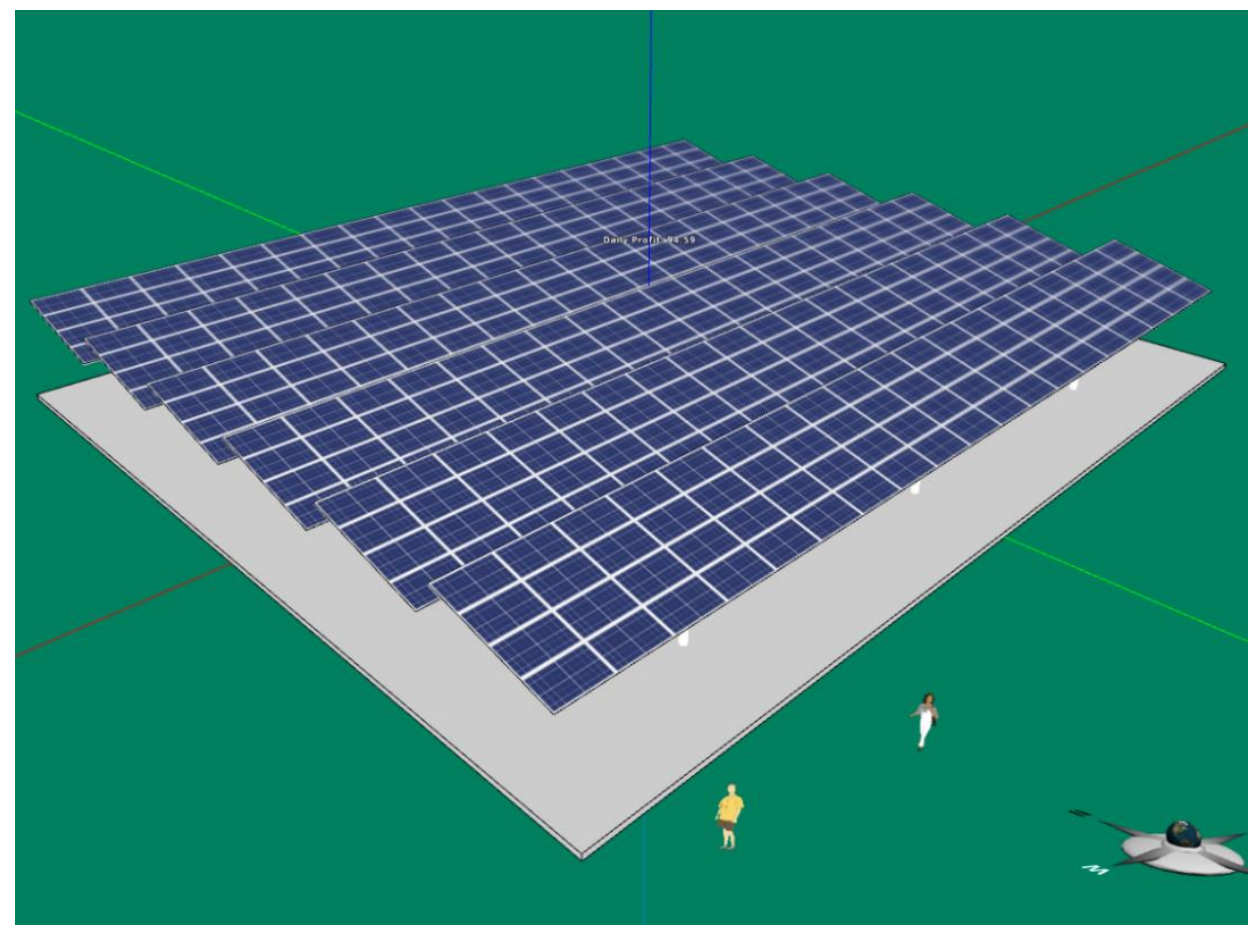

Figure 2: An Example Solar Farm

Designers must manipulate three design variables to improve their solar farm: the tilt angle of a solar panel, the rows of solar panel per rack, and the spacing between adjacent racks. While the design space is constrained to three variables, the variables are interrelated and produce an uneven performance landscape across the design space, eluding simple rules or calculations for an optimal configuration. The design challenge is structured as a divergent-convergent search for a better performing solar farm ${ }^{62}$. The first part focuses on create diverse set of design alternatives. The second part focuses on optimizing promising candidates to identify a more optimal configuration. 


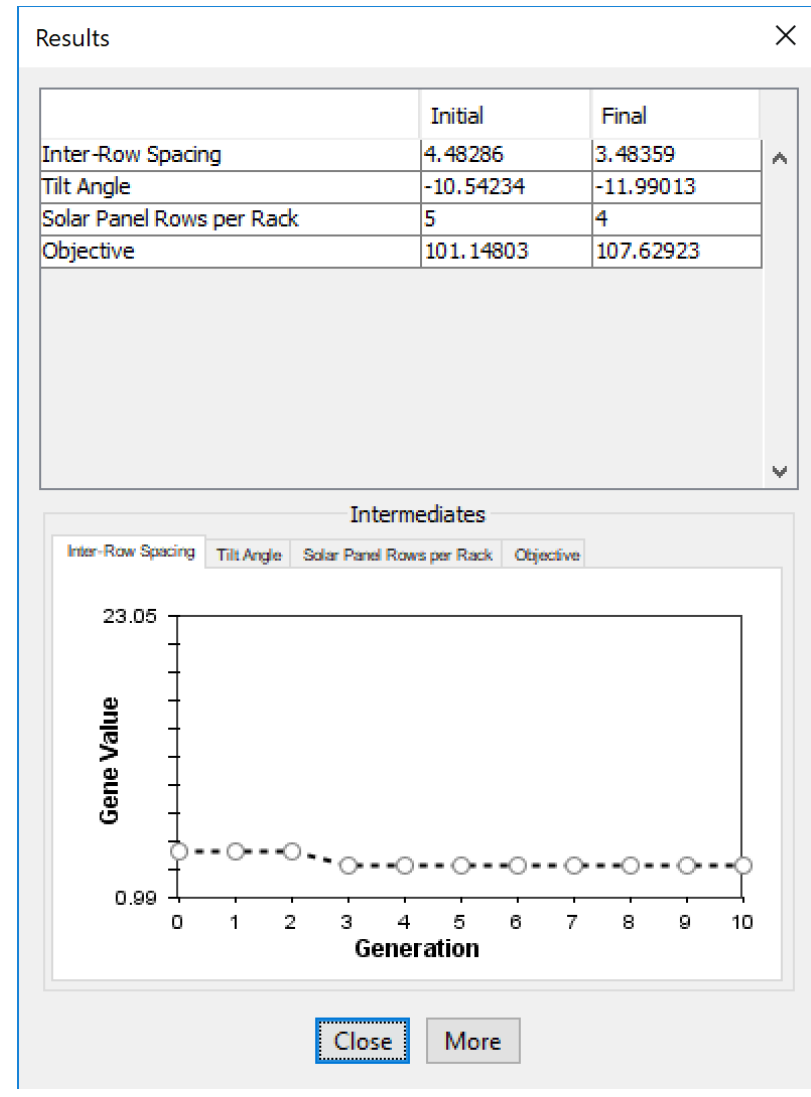

Figure 3: Example Design Agent Feedback

\begin{tabular}{|c|c|}
\hline \multirow[t]{2}{*}{ Instructional Design Agent's Role } & $\begin{array}{l}\text { Bob: Team member who conducts an } \\
\text { exploratory search of the design space }\end{array}$ \\
\hline & $\begin{array}{l}\text { Carol: Team member who conducts a focused } \\
\text { improvement on a small number of design } \\
\text { alternatives }\end{array}$ \\
\hline \multirow[t]{3}{*}{ Human-Agent Interaction } & $\begin{array}{l}\text { Bob: Share several different preliminary } \\
\text { designs emerging from supplied baseline } \\
\text { design }\end{array}$ \\
\hline & $\begin{array}{l}\text { Carol: Improve or refine an existing design } \\
\text { provided by student }\end{array}$ \\
\hline & $\begin{array}{l}\text { Student: Provide Bob with baseline for } \\
\text { diverging and Carol with an advanced design } \\
\text { for refinement. }\end{array}$ \\
\hline Student Role & $\begin{array}{l}\text { Student: Performs parallel design } \\
\text { practices/processes with instructional design } \\
\text { agents, diverging at first and then converging } \\
\text { toward an optimal design. Log agents and } \\
\text { their own designs, submit their final design. }\end{array}$ \\
\hline
\end{tabular}


In design, understanding that a design space may contain several promising designs and no transparent route for identifying the best candidates can be difficult to apprehend for those new to design. A divergent-convergent search process is one method for navigating such a space. However, both of these processes can be difficult. A broad swath of research and design methods have targeted increasing ideation or exploration of new ideas in design ${ }^{61,69}$ to address challenges designers have diverging. At the same time designers have a tendency toward satisficing ${ }^{70}$ or selecting a 'good enough' solution once found, which raises challenges with convergence. Therefore, we sought to scaffold these two design practices with instructional design agents.

Table 2 outlines how this activity maps to the instructional design agent framework. Designers work with two agents who act as team members, Bob and Carol. Bob performs a more exploratory search at the beginning of the design process and Carol assists in refining a design alternative in the second part of the challenge. The student designer performs these actions in parallel; first conducting their own divergent search and then receiving suggestions by Bob. A design log gives the designer space for capturing their own designers and suggestions from Bob. After reviewing these design alternatives, the designer picks a subset of promising alternatives to refine. The designer makes a first attempt to improve the design, and then asks Carol for further improvements. Students are encouraged to iteratively refine their design with Carol, such as identifying changes Carol makes and further improving these to optimize the design further. Students receive either exploratory or refined alternatives in the same format as displayed in Figure 3.

\section{Study Context and Methods}

A pilot study was conducted at a mid-sized university in the southeastern United States. A convenience sample of eighteen junior or senior engineering students participated. Most reported mechanical engineering as their major, with one reporting a sub-focus within mechanical. There were sixteen males and two females. Twelve of the participants were white, two were AfricanAmerican, two were Asian or Pacific Islander, one Native American and one who preferred not to answer.

Students used Energy3D to complete the Divergent-Convergent Solar Farm activity outlined above. Two forms of data were collected. First, each student completed a design log that prompted them to record their designs as well as recommendations from the instructional design agents. Additionally, the design log had prompts for designers to record their reasoning behind key decisions and what design strategies they employed. In particular, the design log asked them to explain their reasoning for selecting a subset of designs to carry into the convergence process and for their strategy for optimizing their design. These questions were covertly intended to also measure Bob and Carol's impact on their design decisions and strategies. Second, students' interactions with Energy3D were logged in the background, such as when they called the AI or changed parameters of their design.

Analysis for this demonstration consists of descriptive reporting of students' and Bob's divergent search as well as highlighting illustrative cases of students interacting with Bob and Carol. Furthermore, we conducted a thematic analysis ${ }^{71}$ on students reasoning behind their selection of 
promising designs and reported design strategies, with an emphasis on how Bob and Carol influenced both of these.

\section{Demonstration Results}

The results first cover students' interactions with and perceptions of Bob's influence on their design process, followed by a presentation of students' interactions and perceptions of Carol's influence on their design process. For Bob, we first report descriptive results about the range of design space exploration students and Bob engaged in, followed by some illustrative examples. We close with a look at students' perceptions of Bob's influence on their decision to carry forward designs to the convergence stage.

\begin{tabular}{|l|l|l|l|}
\hline Table 3 Average Search Range of Students and Bob \\
\hline & Inter-row Spacing & Tilt Angle & SP Per Rack \\
\hline Students & 1.33 & 15.39 & 1.65 \\
\hline Bob & 1.55 & 30.93 & 1.77 \\
\hline
\end{tabular}

Table 3 displays the average search range across the three design variables for all students as well as Bob's suggestions across all students. Individual ranges reflect those reported in each student's design log. Absolute values are used to account for negative values a tilt angle may take. Note that the feasible range for inter-row spacing (measured in meters) and solar panels per rack is approximately 1-10 and 1-6, respectively.

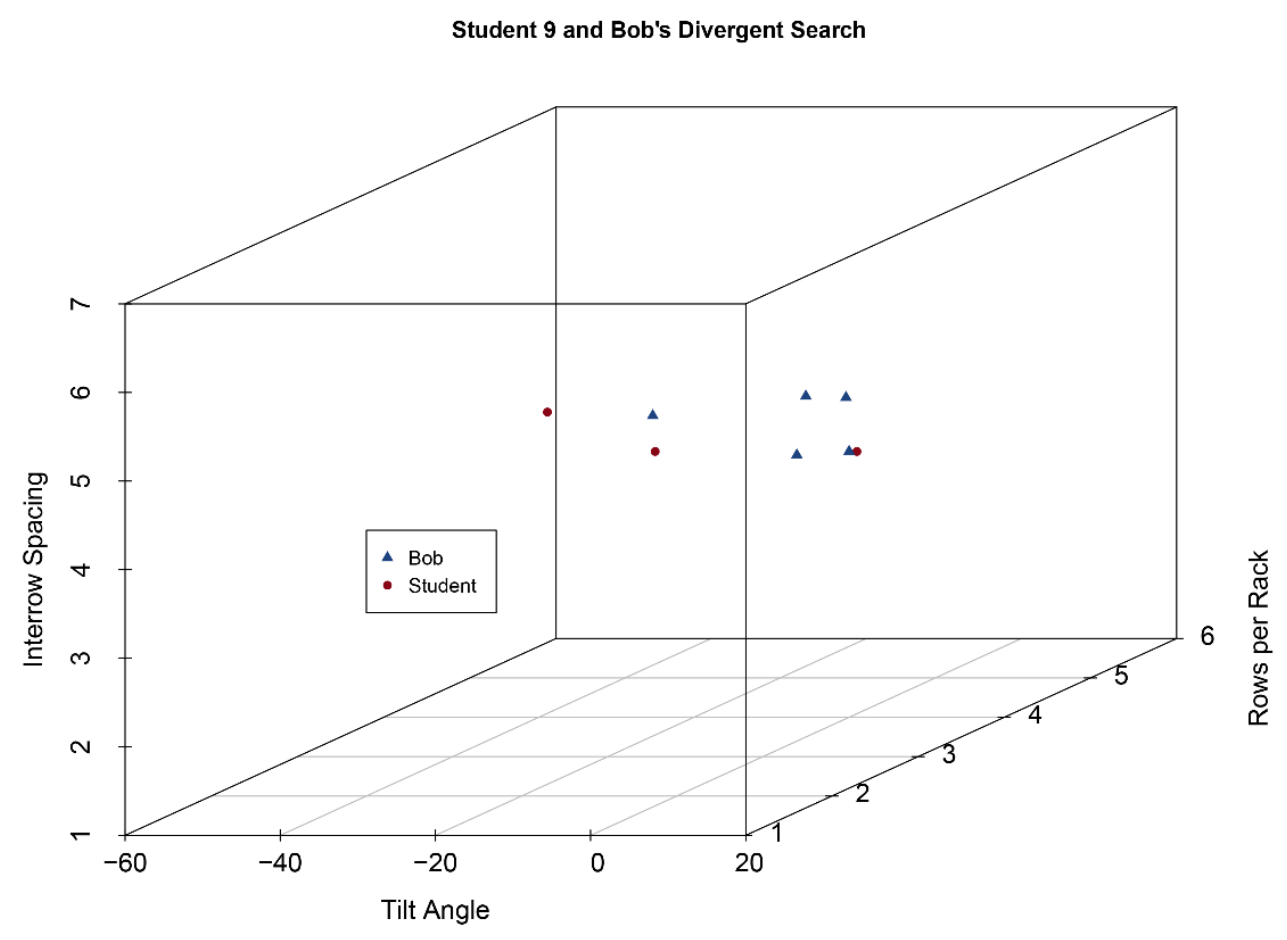

Figure 4: Student 9 and Bob's Search 


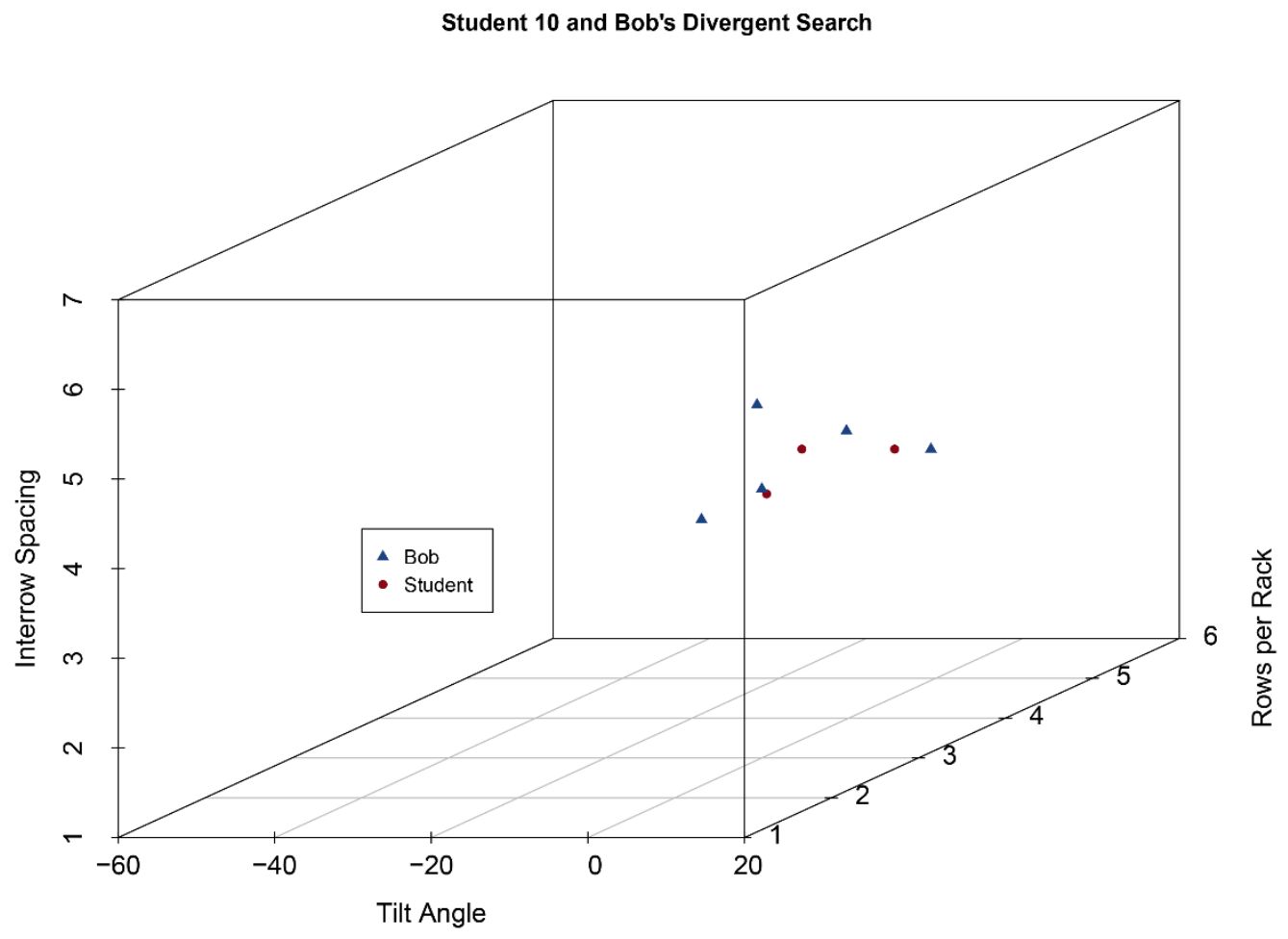

Figure 5: Student 10 and Bob's Search

While the feasible range for tilt angle is -90 to 90 , the realistic range is narrower. From Table 3 the search range of Bob was slightly greater than even fairly advanced students' on average for inter-row spacing and solar panels per rack. Moreover, Bob's average search range was considerable greater than students on tilt angles.

To illustrate the relationship between students and Bob's divergent search, we present two exemplar cases. In the first case, student 9 generally searched across a wider range than Bob, whereas in the second case, student 10 generally searched across a narrower range than Bob. Note that prior clinical trials revealed that students often struggled to come up with more than five divergent design alternatives and this process, combined with logging in their journal required considerable time from students. Therefore, students are asked to generate three designs, whereas Bob generates five, as depicted in the figures.

Turning to student 9 first, Figure 4 displays a 3D scatterplot of Bob and student 9's design alternatives. Across the X-axis, representing tilt angle it can be seen that student 9's designs stretch over a greater range than Bob's and both show some variation across inter-row spacing.

On the other hand, the 3D scatterplot for student 10 and Bob in Figure 5 shows student 10 design alternatives varying across tilt angles with Bob's alternatives stretching beyond these tilt angles as well as presenting designs of greater and fewer solar panels per rack. The range of Bob's search space seems to encompass most of students 10's search. 
Lastly for Bob, we report on a thematic analysis of students' responses to a question in their design log which asked them share their reasoning and motivation for selecting a certain subset of designs to carry forward. A majority of students indicated that the performance of their or Bob's design was the primary factor in selecting a given set of designs to optimization. Aside from this, two other themes emerged. First, a few designers explained that Bob's designs were different than their own and that these designs outperformed their own or appeared to be a promising direction to explore the design space. For instance, student 10 contrasted one of Bob's designs with his own, stating: “...Bob's $5^{\text {th }}$ design has a more drastic angle, so it might be good to experiment with that." And student 13 wrote "I chose Bob Design 4 because it had just a minimal angle. I think small angle will work well for this application because small angle means we can max out the amount of panels because there will be less issue with them overshadowing each other."

A related but broader reflection about Bob's designs was made by a few other designers. They noted that Bob produced a large variety of designs from which they could sample. These students put less emphasis on the immediate performance of Bob's design alternatives and instead focused on the variety. For instance, student 15 states: "I then chose Bob's designs 4 and 5 even though they are not the most efficient ones... because they are two different approaches of Bob considering tilt angle, number of rows per rack and distance, so they might yield different results in the next iterations."

The results now to turn to students' interactions with Carol and reflections on how her suggestions may or may not have affected their own design strategy. Unlike Bob, students seemed less clear on how to leverage Carol to advance their design. Students sometimes submitted early designs to Carol instead of their subset of designs from the divergence stage or abruptly dropped designs entirely instead of iteratively optimizing a design. Therefore, there is less to report for students' interactions with Carol. We first report on some examples of how students iteratively refined their design with Carol and close the section with an analysis of students' perceptions of how Carol may or may not have influenced their design strategy.

\begin{tabular}{|l|l|l|}
\hline Table 4 Student 12 and Carol's Third Refinement \\
\hline & Carol & Student 12 \\
\hline Tilt Angle & -18.56 & -14.5 \\
\hline Solar Panels Rows per Rack & 4 & 5 \\
\hline Inter-row Spacing & 3.49 & 4 \\
\hline Profit & $\$ 101.98$ & $\$ 113.34$ \\
\hline
\end{tabular}

Turning first to illustrative examples of Carol and students interacting, Table 4 displays student 12 and Carol's interaction after Carol's second suggested refinement. Now starting their third revision cycle, student 12 tried several small changes to their solar farm, slightly adjusting the title angle and solar panel rows per rack until arriving at a better performing configuration. Student 12's small adjustments were captured in their design log. With these changes they were able to improve notably on Carol's recommended change, leading to a further refinement of their solar farm. 


\begin{tabular}{|l|l|l|}
\hline Table 5 Student 3 and Carol's Third Refinement \\
\hline & Student 3 & Carol \\
\hline Tilt Angle & -5 & -7.02 \\
\hline Solar Panels Rows per Rack & 5 & 5 \\
\hline Inter-row Spacing & 4.66 & 4.66 \\
\hline Profit & $\$ 98.19$ & $\$ 98.28$ \\
\hline
\end{tabular}

In contrast to Table 4, Table 5 starts with student 3's second iteration, followed by Carol's recommendation. Based on student 3's solar farm, Carol returns a slightly improved design. The improvement is marginal, producing only a few cents more than student 3's design, despite there being considerable room for improvement. In this example, Carol is unable to find any stronger improvement.

In their responses to the design log prompt about their design strategies, many students reported adjusting one parameter at a time as their primary strategy for refining their design. Additionally, a few students expressed surprise at changes Carol made to the design, explaining her changes were more dramatic than they expected or in a direction they were not considering. For example, student 7 stated "Carol showed me that I needed to make more drastic changes to my design instead of trying to fine-tune the small details" and student 15-2 shared "The way AI thought in the last revise was much different to what I was thinking." Although this stage was intended as a convergence stage both Carol and student's saw opportunities for changes beyond small calibration tweaks. A more conservative theme emerged from a few other designers who described carefully watching changes Carol made to the solar farm and using her recommendations for further adjustments. For instance, student 11 shared that they revised their design by "Setting values lower or higher than Carol's design and revising from there." This set of students did not mention any surprising or pronounced changes from Carol, suggesting their revisions may have been on a smaller scale.

\section{Discussion of Demonstration}

A number of observations can be made from this pilot study for scaffolding divergentconvergent solar farm design. First, Bob shows some promise as an instructional design agent. On average, his range of designers were near or exceeded the range of designs explored by this set of relatively more experienced junior and senior engineers. For designers who are unsure of promising directions in the design space, Bob was able to generate a variety of designs for them to consider. It is important to note that Bob's range was larger on average while simultaneously always representing an improvement or the same performance in design, which may not always hold for students' exploration. In their written responses to how they decided to select a subset of design alternatives to carry into the convergence stage, some designers reported seeing unexpected designs from Bob while others emphasized the variety of designs Bob generated. In both ways, Bob helped scaffold students' exploration of the design space.

Second, Carol's interaction with students was more mixed. Many students continued to explore different design possibilities or did not advance the designs they had selected from the first stage. Students who did attempt to revise their designs were sometimes able to gain something by 
adjusting Carol's design, but sometimes Carol returned design alternatives with minimal improvement. This particular point represents a challenge we faced in selecting an appropriate search strategy for Carol. While a longer search would likely ensure at least a modest improvement to recommend to students, this would also inhibit the design process as students would have to wait longer for Carol to recommend something.

Third, a more general point, is that students sometimes observed ideas from Bob and Carol and other times seemed to pay less attention to their suggestions. In the spirit of design and authentic project-based learning we sought avoid making an overly guided design challenge, however, in a challenge scaffolded by instructional design agents, it is important for students to learn and reflect on their interactions with the agents. In other work with intelligent agents, some researchers have focused on humanizing agents to make them more relatable and increase students recognition and interaction with them ${ }^{39,72}$. These are often called pedagogical agents. This may be a promising route for future development of our instructional design agents.

The results presented here demonstrate the feasibility of using instructional design agents to teach a divergent-convergent design process, while noting some difficulties particularly with scaffolding the convergence process. We have begun to revise this part of the activity due to student confusion, removing some of the documentation and making the flow of the activity clearer, with future tests of the activity planned. More broadly, this demonstration shows some preliminary evidence that the instructional design agents framework may work to help scaffold inexperienced and novice designers' introduction and exposure to the design process.

\section{Conclusions, Limitations and Future Work}

The work presented in this manuscript has some important limitations. The project demonstrated here is early in development and needs further refinement. The population studied was a convenience sample for testing and developing our instructional design agent system; the activity and system itself needs to be run with less experienced designers in K-12 settings and early or first year engineering students to fully understand its affordances and limitations as a means of scaffolding design education. At a broader level, more work is needed to identify the strengths and weaknesses of the instructional design agent framework proposed here, including the depth of design challenges it can support. It should be acknowledged that implementing an instructional design agent system will require dedicated time and effort and may be best handled through collaborative partnerships between researchers, teachers and developers, where possible.

This work proposed the instructional design agents as a means for scaffolding the challenges early and novice designers have in learning this complex set of practices, strategies and processes. The instruction design agent framework was introduced to delineate the core pedagogical and technological components of these agents and the kinds of decisions design educators and researchers will need to consider in creating such agents. Ongoing work in developing design agents for a solar farm design challenge was used to demonstrate how these agents might support students divergent and convergent search processes. Pilot results indicate the divergent agent has some positive affect while the other, convergent agent is more mixed. This provides some initial evidence that design agents may be a useful way to scaffold students' 
design learning but also points to challenges in properly calibrating design agents to assist students, encouraging student interaction with agents, integrating agents and associated curriculum and the need for developing other types of agents in other design contexts.

In future work we aim to continue to revise the divergence-convergence activity reported here and start running the activity with collaborators in early engineering programs as well as high school teachers interested in bringing this approach into their classrooms. We will also experiment with ways to further humanize Bob and Carol drawing on ideas from pedagogical agent research ${ }^{39,72}$.

The potential of AI to empower and assist students in design and other complex fields of study remains an open question and vast opportunity for research, development and pedagogical innovations. This holds especially true as human-technology collaboration weighs heavily toward further expansion and changing the nature of how students will work in their future careers.

\section{Acknowledgements}

The authors thank the National Science Foundation for support of this research (Award 1503196: SmartCAD: Guiding Engineering Design with Science Simulations). The views expressed herein are solely the authors'.

\section{Citations}

1. Flasiński, M. (2016). Introduction to artificial intelligence. New York, NY: Springer Berlin Heidelberg.

2. Silver, D., Huang, A., Maddison, C. J., Guez, A., Sifre, L., van den Driessche, G., ... Hassabis, D. (2016). Mastering the game of Go with deep neural networks and tree search. Nature, 529(7587), 484-489.

3. National Science Foundation. Future of Work at the Human-Technology Frontier. Retrieved from: https://www.nsf.gov/publications/pub_summ.jsp?ods_key=nsf19541 (2/3/19).

4. Egan, P., Cagan, J., Schunn, C., \& LeDuc, P. (2015). Synergistic human-agent methods for deriving effective search strategies: the case of nanoscale design. Research in Engineering Design, 26(2), 145-169.

5. Campbell, M. I., Cagan, J., \& Kotovsky, K. (2003). The A-Design approach to managing automated design synthesis. Research in Engineering Design, 14(1), 12-24.

6. Cvetkovic, D., \& Parmee, I. (2002). Agent-based support within an interactive evolutionary design system. Artificial Intelligence for Engineering Design, Analysis and Manufacturing, 16, 331-342.

7. Bull, S. (2016). Negotiated learner modelling to maintain today's learner models. Research and Practice in Technology Enhanced Learning, 11(1).

8. Ritter, S., Anderson, J. R., Koedinger, K. R., \& Corbett, A. (2007). Cognitive Tutor: Applied research in mathematics education. Psychonomic Bulletin \& Review, 14(2), 249-255.

9. VanLehn, K., Lynch, C., Schulze, K., Shapiro, J. A., Shelby, R., Taylor, L., ... Wintersgill, M. (2005). The Andes Physics Tutoring System: Lessons Learned. International Journal of Artificial Intelligence in Education, 15(3), 48.

10. Murray, T. (1999). Authoring Intelligent Tutoring Systems: An analysis of the state of the art. International Journal of Artificial Intelligence in Education, 10 98-129.

11. Crismond, D. P., \& Adams, R. S. (2012). The informed design teaching and learning matrix. Journal of Engineering Education, 101(4), 738-797.

12. Atman, C. J., Cardella, M. E., Turns, J., \& Adams, R. (2005). Comparing freshman and senior engineering design processes: an in-depth follow-up study. Design Studies, 26(4), 325-357.

13. Atman, C. J., Chimka, J. R., Bursic, K., M., \& Nachtmann, H., L. (1999). A comparison of freshman and senior engineering design processes. Design Studies, 20, 131-152. 
14. National Research Council (NRC). (2012). A Framework for K-12 Science Education: Practices, Crosscutting Concepts, and Core Ideas. Washington, D.C.: The National Academies Press.

15. Hynes, M. M. (2012). Middle-school teachers' understanding and teaching of the engineering design process: a look at subject matter and pedagogical content knowledge. International Journal of Technology and Design Education, 22(3), 345-360.

16. Yaşar, Ş., Baker, D., Robinson-Kurpius, S., Krause, S., \& Roberts, C. (2006). Development of a Survey to Assess K-12 Teachers' Perceptions of Engineers and Familiarity with Teaching Design, Engineering, and Technology. Journal of Engineering Education, 95(3), 205-216.

17. Gu, N., Gul, L., F., Williams, A., \& Nakapon, W. (2009). Second Life: A Context for Design Learning. In Higher education in Virtual Worlds: Teaching and Learning in Second Life (pp. 159-180). Emerald Group Publishing Limited.

18. Legg, S., \& Hutter, M. (2007). A Collection of Definitions of Intelligence. Frontiers in Artificial Intelligence and Applications, 157, 17-24.

19. Horst, J. (2002). A native intelligence metric for artificial systems. In Performance Metrics for Intelligent Systems Workshop, Gaithersburg, MD, USA.

20. Franklin, S., \& Graesser, A. (1996). Is it an Agent, or just a Program?: A Taxonomy for Autonomous Agents. In International Workshop on Agent Theories, Architectures, and Languages (pp. 21-35). Springer, Berlin, Heidelberg.

21. Wooldridge, M., \& Jennings, N. R. (1995). Intelligent agents: Theory and practice. The knowledge engineering review, 10(2), 115-152.

22. Graesser, A. C., Chipman, P., Haynes, B. C., \& Olney, A. (2005). AutoTutor: An intelligent tutoring system with mixed-initiative dialogue. IEEE Transactions on Education, 48(4), 612-618.

23. Arroyo, I., Royer, J. M., \& Woolf, B. P. (2011). Using an intelligent tutor and math fluency training to improve math performance. International Journal of Artificial Intelligence in Education, 21(1-2), 135-152.

24. Ma, W., Adesope, O. O., Nesbit, J. C., \& Liu, Q. (2014). Intelligent tutoring systems and learning outcomes: A meta-analysis. Journal of Educational Psychology, 106(4), 901.

25. Cai, Z., Feng, S., Baer, W., \& Graesser, A. (2014). Instructional Strategies in Trialogue-based Intelligent Tutoring Systems.

26. Nkambou, R., Bourdeau, J., \& Psyché, V. (2010). Building Intelligent Tutoring Systems: An Overview. In R. Nkambou, J. Bourdeau, \& R. Mizoguchi (Eds.), Advances in Intelligent Tutoring Systems (Vol. 308, pp. 361-375). Berlin, Heidelberg: Springer Berlin Heidelberg.

27. Graesser, A. C., Lu, S., Jackson, G. T., Mitchell, H. H., Ventura, M., Olney, A., \& Louwerse, M. M. (2004). AutoTutor: A tutor with dialogue in natural language. Behavior Research Methods, Instruments, \& Computers, 36(2), 180-192.

28. Butz, B. P., Duarte, M., \& Miller, S. M. (2006). An Intelligent Tutoring System for Circuit Analysis. IEEE Transactions on Education, 49(2), 216-223.

29. Biwas, S., Sendaula, M., Yeruva, S., Sannidhi, K.P. \& Dwivedula, R.S. (2006). An Intelligent Interactive Tutoring System for an Electronic Circuits Course. 113th ASEE Annual Conference \& Exposition. Presented at the American Society for Engineering Education Annual Conference, Chicago, IL.

30. Hagge, M., Amin-Naseri, M., Jackman, J., Guo, E., \& Gilbert, S. B. (2017). Intelligent Tutoring System Using Decision Based Learning for Thermodynamic Phase Diagrams. Phase Diagrams, 22.

31. Nesbit, J.C., Liu, L, Liu, Q \& Adescope, O.O. (2015). Work in Progress: Intelligent Tutoring Systems in Computer Science and Software Engineering Education. 122nd ASEE Annual Conference \& Exposition. Presented at the American Society for Engineering Education Annual Conference, Seattle, WA.

32. Hsieh, S.-J., \& Hsieh, P. Y. (2001). Intelligent Tutoring System Authoring Tool for Manufacturing Engineering Education. International Journal for Engineering Education, 17(6), 569-579.

33. Gong, N., Biswas, S., Bai, L, \& Butz, B.B. (2016). An Intelligent Tutoring System for Multimedia Virtual Power Laboratory. 123nd ASEE Annual Conference \& Exposition. Presented at the American Society for Engineering Education Annual Conference, New Orleans, LA.

34. Shahani, H., Biwas, S., Sendaula, M. \& Palilla, H. (2004). An Intelligent Interactive Tutoring System For Engineering Education. 111th ASEE Annual Conference \& Exposition. Presented at the American Society for Engineering Education Annual Conference, Salt Lake City, UT. 
35. Kim, Y., \& Baylor, A. L. (2016). Research-based design of pedagogical agent roles: A review, progress, and recommendations. International Journal of Artificial Intelligence in Education, 26(1), 160-169.

36. Kim, Y., \& Baylor, A. L. (2006). Pedagogical agents as learning companions: The role of agent competency and type of interaction. Educational Technology Research and Development, 54(3), 223-243.

37. Rickel, J. (2001, September). Intelligent virtual agents for education and training: Opportunities and challenges. In International Workshop on Intelligent Virtual Agents (pp. 15-22). Springer, Berlin, Heidelberg.

38. Baylor, A. (2000). Beyond Butlers: Intelligent Agents as Mentors. Journal of Educational Computing Research, 22(4), 373-382.

39. Veletsianos, G., \& Russell, G. S. (2014). Pedagogical agents. In Handbook of research on educational communications and technology (pp. 759-769). Springer, New York, NY.

40. Aleven, V. A., \& Koedinger, K. R. (2002). An effective metacognitive strategy: Learning by doing and explaining with a computer-based Cognitive Tutor. Cognitive science, 26(2), 147-179.

41. Hu, Y. \& Taylor, M.E. (2016). WORK IN PROGRESS: A Computer Aided Design Intelligent Tutoring System Teaching Strategic Flexibility. 123rd ASEE Annual Conference \& Exposition. Presented at the American Society for Engineering Education Annual Conference, New Orleans, LA.

42. McComb, C., Cagan, J., \& Kotovsky, K. (2015). Lifting the Veil: Drawing insights about design teams from a cognitively-inspired computational model. Design Studies, 40, 119-142.

43. Campbell, M. I., Cagan, J., \& Kotovsky, K. (1999). A-Design: An Agent-Based Approach to Conceptual Design in a Dynamic Environment. Research in Engineering Design, 11(3), 172-192.

44. Brown, D. C., Dunskus, B. V., Grecu, D. L., \& Berker, I. (1995). SINE: Support for Single Function Agents. Proceedings of the International Conference on Artificial Intelligence in Engineering, Udine, Italy

45. Wang, J., \& Terpenny, J. (2003). Interactive evolutionary solution synthesis in fuzzy set-based preliminary engineering design. Journal of Intelligent Manufacturing, (14), 153-167.

46. Quadrel, R. W., Woodbury, R. F., Fenves, S. J., \& Talukdar, S. N. (1993). Controlling asynchronous team design environments by simulated annealing. Research in Engineering Design, 5(2), 88-104.

47. Efatmaneshnik, M., \& Reidsema, C. (2009). IMMUNE: A Collaborating Environment for Complex System Design. In C. L. Mumford \& L. C. Jain (Eds.), Computational Intelligence (Vol. 1, pp. 275-320). Berlin, Heidelberg: Springer Berlin Heidelberg.

48. Hanna, L., \& Cagan, J. (2009). Evolutionary Multi-Agent Systems: An Adaptive and Dynamic Approach to Optimization. Journal of Mechanical Design, 131(1).

49. McComb, C., Cagan, J., \& Kotovsky, K. (2016). Drawing Inspiration From Human Design Teams for Better Search and Optimization: The Heterogeneous Simulated Annealing Teams Algorithm. Journal of Mechanical Design, 7.

50. McComb, C., Cagan, J., \& Puentes, L. (2018). A Two-Tiered Grammatical Approach for Agent-based Computational Design. In Proceedings of the ASME 2018 International Design Engineering Technical Conferences \& Computers in Engineering Conferences. Quebec City, Canada.

51. McComb, C., Cagan, J., \& Kotovsky, K. (2017). Capturing Human Sequence-Learning Abilities in Configuration Design Tasks Through Markov Chains. Journal of Mechanical Design, 139(9), 091101.

52. Beuth, J.L., Kumar, R. \& Rose, C.P. (2011). Use of Software Agent Monitored Tutorials to Guide Student Learning in Computer-Aided-Design, Analysis and Mathematics Projects. 118th ASEE Annual Conference \& Exposition. Presented at the American Society for Engineering Education Annual Conference, Vancouver, Canada.

53. Ball, L. J., \& Christensen, B. T. (2009). Analogical reasoning and mental simulation in design: two strategies linked to uncertainty resolution. Design Studies, 30(2), 169-186.

54. Simon, H. A. (1997). Models of Bounded Rationality, MIT Press: Cambridge, MA.

55. Crilly, N., \& Cardoso, C. (2017). Where next for research on fixation, inspiration and creativity in design? Design Studies, 50, 1-38.

56. Quintana, C., Reiser, B. J., Davis, E. A., Krajcik, J., Fretz, E., Duncan, R. G., ... Soloway, E. (2004). A Scaffolding Design Framework for Software to Support Science Inquiry. Journal of the Learning Sciences, 13(3), 337-386. 
57. Sharma, P., \& Hannafin, M. J. (2007). Scaffolding in technology-enhanced learning environments. Interactive Learning Environments, 15(1), 27-46.

58. Oplinger, J.L. \& Lande, M. (2014). Measuring Qualities of Different Engineering Design Models: A Critical Review. 121st ASEE Annual Conference \& Exposition. Presented at the American Society for Engineering Education Annual Conference, Indianapolis, IN.

59. Russell, S. \& Novig, P. (1995). Artificial Intelligence: A Modern Approach. Prentice-Hall, Inc: Upper Saddle River, NJ.

60. Newell, A. \& Simon, H.A. (1976). Computer science as empirical enquiry: Symbols and search. Communications of the ACM 19, 3:113-126.

61. Daly, S. R., Yilmaz, S., Christian, J. L., Seifert, C. M., \& Gonzalez, R. (2012). Design Heuristics in Engineering Concept Generation. Journal of Engineering Education, 101(4), 601-629.

62. Dym, C. L., Agogino, A. M., Eris, O., Frey, D. D., \& Leifer, L. J. (2005). Engineering Design Thinking, Teaching, and Learning. Journal of Engineering Education, 94(1), 103-120.

63. Klein, G., Woods, D. D., Bradshaw, J. M., Hoffman, R. R., \& Feltovich, P. J. (2004). Ten Challenges for Making Automation a "Team Player" in Joint Human-Agent Activity. IEEE Intelligent Systems, 19(06), 91-95.

64. Idoughi, D., Seffah, A., \& Kolski, C. (2012). Adding user experience into the interactive service design loop: a persona-based approach. Behaviour \& Information Technology, 31(3), 287-303.

65. Miaskiewicz, T., \& Kozar, K. A. (2011). Personas and user-centered design: How can personas benefit product design processes? Design Studies, 32(5), 417-430.

66. Albacete, P. L., \& VanLehn, K. (2000). Evaluating the Effectiveness of a Cognitive Tutor for Fundamental Physics Concepts. In Proceedings of the Annual Meeting of the Cognitive Science Society (Vol. 22, p. 7).

67. Melis, E., \& Siekmann, J. (2004). ActiveMath: An Intelligent Tutoring System for Mathematics. In L. Rutkowski, J. H. Siekmann, R. Tadeusiewicz, \& L. A. Zadeh (Eds.), Artificial Intelligence and Soft Computing - ICAISC 2004 (Vol. 3070, pp. 91-101). Berlin, Heidelberg: Springer Berlin Heidelberg.

68. Xie, C. Schimpf, C. Chao, J. Nourian, S. \& Massicotte, J. (2018). Learning and teaching engineering design through modeling and simulation on a CAD platform. Computer Applications in Engineering Education, pp. 1-17.

69. Nelson, B. A., Wilson, J. O., Rosen, D., \& Yen, J. (2009). Refined metrics for measuring ideation effectiveness. Design Studies, 30(6), 737-743.

70. Simon, H., A. (1996). The Sciences of the Artificial. MIT Press: Cambridge, MA.

71. Braun, V., \& Clarke, V. (2006). Using thematic analysis in psychology. Qualitative Research in Psychology, 3(2), 77-101.

72. Schroeder, N. L., \& Adesope, O. O. (2012). A Case for the use of Pedagogical Agents in Online Learning Environments. Journal of Teaching and Learning with Technology, 1(2), 43 - 47. 